\title{
From the Editor: Signs of the Times
}

\author{
Dorothy S. Becvar
}

Published online: 7 August 2010

(C) Springer Science+Business Media, LLC 2010

Some of the questions often heard when students as well as other mental health professionals are introduced to a systems perspective, with its focus on context and relationships, is "What about the individual person?" and "Where does he or she fit?" Given a society in which individualism is one of its most cherished values, such questions, and the fears from which they likely are derived, make perfect sense. However, these fears are unfounded given the fact that families and relationships are comprised of individuals, understanding of whom is essential if the work of the family therapist is to be as effective as possible. Nevertheless, despite such reassurances, the early literature in the marriage and family therapy (MFT) field was characterized primarily by articles focusing on relationship dynamics. This certainly was appropriate given the paradigm shift of a cybernetic epistemology and the excitement it generated as the focus moved away from the internal dynamics of the individual mind to a consideration of systems in general and families in particular.

But, "the times they are a changin'." In light of the fact that the pendulum always tends to swing back, as well as the reality that MFT has aged a bit as a profession, we now see more of a balance throughout the literature. And this certainly is the case here, as illustrated by the topics, as well as the number of articles in each of the categories into which the articles in this issue seemed to fall. These categories include (1) a focus on individuals; (2) a focus on the parental and spouse subsystems; (3) a focus on family dynamics relative to obesity; and (4) a focus on training, albeit with a relatively new twist.

In the individual category, Kristen Williams and Sarah Francis studied and have written about "Parentification and Psychological Adjustment: Locus of Control as a Moderating Variable." A second article, also with more of an individual focus, provided by Z. Seda Sahin, David Nalbone, Joseph Wetchler, and Jerry Bercik, is titled "The Relationship of Differentiation, Family Coping Skills, and Family Functioning with Optimism in CollegeAge Students." Then, moving from the undergraduate to the graduate level, Raquel Delevi amd Ash Bugay had as their goal "Understanding Change in Romantic Relationship

D. S. Becvar $(\bowtie)$

Saint Louis University, St. Louis, MO, USA

e-mail: becvard@aol.com; becvards@slu.edu 
Expectations of International Female Students from Turkey," a description of which is provided.

In the second category, in which the focus is on the parental and spouse subsystems, the first article describes, "Parents' Perception of Their First Encounter with Child and Adolescent Psychiatry" as noted by Monica Hartzell, Jaakko Seikkula, and Anne-Liis von Knorring. This article is a sequel to an earlier article by the first author in which the focus was on the children and adolescents in the same setting. Next, John Beckenbach, Shawn Patrick, and James Sells have contributed "Relationship Conflict and Restoration Model: A Preliminary Exploration of Concepts and Therapeutic Utility." And in "'Broken Together': Spirituality and Religion as Coping Strategies for Couples Dealing with the Death of a Child: A Literature Review with Clinical Implications," Ileana Ungureanu and Jonathan Sandberg explore a topic that will be significant for therapists who work in the realm of bereavement.

The third category, comprised of two articles that focus on family dynamics relative to obesity, is becoming more and more prevalent and important both in this country and internationally. In the first article, "Associations among Body Mass Index, Depression and Family Factors Across Two Generations" were explored by Lisa Hooper, Mark Richardson, Linda Knol, Nyshetia White-Chapman, \& Natalie Hannah. And Oi Ling Wong studied "Childhood Obesity in a Chinese Family Context."

Finally, focusing on training, Christopher Latty, Jeffrey Augera, and Kathleen BurnsJager describe their efforts aimed at "Socializing Undergraduates to the MFT Field," a topic that up to now has received very little attention. Indeed, it seems appropriate to recognize the importance of educating students about the MFT field early in their academic careers.

As the pendulum continues to swing, there is little doubt that new and different categories will evolve, and other issues will rise to the fore. Certainly that is appropriate. Also appropriate will be the need to step back periodically and take a measure of what the signs of the times seem to be telling us about our individual work and our profession as a whole. At this point, my reading of the signs is that we seem to be about innovation in the context of balance-a nice place to be. 